Search Fields for Radical

Innovations involving Market Research

Cornelius Herstatt

September 2001

Paper No. 10 


\title{
Search Fields for Radical Innovations involving Market Research
}

\section{by Cornelius Herstatt*}

\begin{abstract}
"Strong market orientation is essential for innovation success!" Although both academics and market research practitioners would generally accept this statement, alignment with the needs of the customer often results in conservative innovation strategies. Due to their focus on what is currently on offer in the marketplace, customers primarily demand so-called incremental innovations. Companies however, want to develop entry points for radical innovations. The identification of radical innovations is a difficult task whose implementation is often associated with significant risk. It is questionable if market research can alone allow innovation management to develop attractive search fields for radical innovations and if it can also contribute to the reduction of the risk that such innovations inherently possess. Closer observation shows that the market research methods used today for the discovery of radical innovations in the form of new market/technology combinations possess only limited suitability. Empirical tests verify that successfully innovative companies often don't use such methods, rather they involve specifically qualified, innovative knowledge carriers early-on in the process such as Lead Users or external experts with relevant knowledge from analogous markets in the search for innovations. When searching for applications for radical innovations, market researchers should initially concentrate on the question of who they address as the information source. How successful the process of involving experts is and how well supported through the methodology it is, depends heavily on the specific factors and conditions related to the project planning.
\end{abstract}

\section{Introduction}

The adding of value in a company via innovation, demands the identification of attractive innovation fields, the creation of new products and services as well as their successful implementation in the market. The higher the degree of innovation (market/technological), the greater the risks involved that stand in the way of its successful realization. Technical, market, temporal or costrelated risks all play a role here. Well known product "flops" like the New Coke, the Apple Newton, the Videodisc or the Commodore computer verify that even large companies, experienced in market research, are not protected from such risks. An important goal of innovation management should therefore be to make the inherent risks associated with innovation more transparent and therefore more manageable. It is here that market research plays a central role. Market research should support innovation management in two respects in particular:

1) in the generation of the most attractive as possible points of entry for product and process innovations in known as well as in as yet undeveloped application fields and

2 ) in the reduction of the risks associated with innovations, in particular the inherent marketing risks that grow with increasing degree of innovation (Schlaak, 1999). How well equipped is market research for this task? We will examine this question in the following discussion.

In the following section we will discuss the suitability of different market research methods with particular reference to their ability to produce information for radical innovations. In Section 3, we will outline how, despite marked customer and/or market orientation, market research can support innovation management through developing search fields, ideas and concepts for radical

\footnotetext{
*Prof. Dr. Cornelius Herstatt is the head of department for Technologiy and Innovation Management, Technical
} University of Hamburg-Harburg, Germany; E-Mail: herstatt@,tu-harburg.de; Internet. www.tu-harburg.de/tim 
innovations. Section 4 introduces a typology of different users who can be involved in innovation projects with differing degrees of innovation. In conclusion, Section 5 addresses gaps in the research and questions that derive from these.

\section{The suitability of market research for the generation of radical innovations}

Innovations can be basically ordered via the dimensions "Method" and "Purpose" and with respect to their degree of novelty (Diagram 1).

Diagram 1: Innovations with differing degrees of novelty

Source: Hausschildt (1997)

Radical product innovations are those that satisfy a new need through the utilization of a new technology or one not yet applied in that form. One characteristic of radical innovations is that the market as well as the technological uncertainty is at maximum (Lynn, 1992). What can market research contribute to the satisfying of a new need, the recognition of a new technology and the reduction of market and technological uncertainties?

Market research is occupied in particular with the question of obtaining information for innovations. Market research is applicable where both the inherent market and/or customer needs are evident as well as (Herstatt, 1991) where, depending upon the topic in question, different methods can be applied like survey techniques, observations, creativity techniques or combined processes (for example focus groups, video-supported observations/questioning, laboratory tests etc.) (Herstatt/Geschka, 1991).

Practical experience shows that direct research with customers and users delivers good results for incremental innovations, whereas for purpose/method induced innovations they produce good results only occasionally and for radical innovations the results are usually unusable. Why? Conventional market research methods such as customers surveys and focus group discussions are inherently more short-term focused (orientation on the customers of today) and due to their alignment with the existing product program, lead to the development of small improvements in existing products. The market information need of radical innovation projects is however orientated towards the future (orientation on customers and markets from tomorrow). Further, methodical reasons as to why the suitability of market research is limited for radical innovations are:

$\rightarrow$ Market research strives for representative statements and therefore is focused more on the average user or customer, who is scarcely unable to articulate his needs or doesn't realize that they even exist.

$\rightarrow$ Market research requires a multitude of testing and therefore value is placed on the application of quantitative methods that provide a base for easier comparison. Interesting applications for new needs (e.g. new sports like kite surfing or downhill mountain biking that are followed by a small group of passionate amateur sport fans) won't be captured in this way.

Radical innovation projects demand stronger explorative and anticipatory market research methods that are capable of determining the current needs of the customer (Deszca, 1999; Lender, 1991). Empirical test show that companies involved with radical innovation projects rarely report about the application of advanced market research methods (Geschka/Herstatt, 1999). Processes 
that could be applied in such circumstances, for example "Empathic Design", are still in their infancy (more on this; Herstatt/Lettl, 2000).

Burton and Patterson recommend, depending upon the desired degree of innovation, the application of differing processes (see Diagram 2). The empirical verification of the effectiveness of these techniques as well as the use of the processes recommended here is still yet to be determined.

Diagram 2: Market research for innovations of differing degrees of novelty

Source: Burton/Patterson, (1999)

On the other hand, examination of research success factors for innovation (Lüthje 1999; Gruner 1996; Kirchmann 1994;) consistently reinforces how important the early involvement of customers is for the later success of the innovation (discriminating factor). The work of Lüthje (1999) and Gruner (1996) emphasizes that individual characteristics of the people involved has a significant influence on the eventual success of the analyzed innovation projects. The actual form of the user involvement and the methodology applied to do had however no significant influence on the innovation success (Gruner 1996).

Which characteristics however do (particularly) innovative users possess? Is it possible to differentiate between innovative and non-innovative users? Are the relevant characteristics able to be quantified allowing producers to use them to identify innovative users early on in a development project? In order to answer these questions, one has to determine exactly who it is that innovates (the source of the innovation). Since the mid- '80's, von Hippel has focused on this area of research. It has been shown through his own work as well as that of his students, that it is not only manufacturers that play a crucial role in the development of innovations in varying industries but also users ("Lead Users") and suppliers ("Lead Suppliers"). The analysis of von Hippel and others centered on incremental as well as radical product and process innovations. Recent test also emphasize the role that innovative users play in the development of new products in industrial as well as in consumer goods (see Diagram 3).

Diagram 3: Who innovates? Current research in user innovations

Source: Herstatt/Lüthje/Lettl (2001)

It is obviously of interest for a manufacturer to identify innovative users or suppliers early on in order to check the innovation potential of the development work and, if necessary, to channel new products and processes. The question is, how this identification process should be managed and if such users allow for identification based on specific characteristics. The Lead User model (von Hippel 1988) gave a first indication of particular characteristics that differentiate innovative from non- innovative users:

- Lead users face needs that will be general in the marketplace-but face them months or years before the bulk of that marketplace encounters them, and

- Lead users are positioned to benefit significantly by obtaining a solution to those needs.

The research from Lüthje in the area of outdoor and trekking clothing showed further that innovative behavior by the users was the result of and could be explained by the existence of a new user-need that wasn't being satisfied by the present product range of a manufacturer (Lüthje, 
1999). Dissatisfaction with existing products, application knowledge and technical experience was of medium importance whilst the general motivation (e.g. pursuing economic goals) played clearly a lesser role.

This set of characteristics or properties was confirmed in the work of Shah (2000). The thought that innovative and non-innovative users can be differentiated and, at least for the branches researched, specific characteristics have a role to play in this appeared to have been proven.

The quality of user innovations, in our opinion, still hasn't been explicitly researched. But multiple examples of realized user innovations in the marketplace indicate that such products which are traceable back to user activities can also be successfully established in mass markets (e.g. mountain bikes, surf and snow boards, the successful web software Apache, the sports drink Gatorade and many more). From the analysis of 47 innovation projects at $3 \mathrm{M}$, Morrison et al. found out that those projects in particular that were carried out together with Lead Users proved significantly more successful in terms of turnover and degree of innovation than projects that were internally undertaken and developed with the use of standard market research methods (e.g. focus groups with average users or brainstorming sessions) (Morrison et al. 2000).

The bandwidth of innovation activities in the example of German surgeons is shown in a current survey of this professional group (Diagram 4).

Diagram 4: Innovation activities of German surgeons

Source: Own tests

Why, however, do users become innovative at all? What knowledge with regard to the motivation of innovative users can be derived from such tests that could be of use for Innovation Management (e.g. prognostic and usable characteristics that would allow the separation into innovative versus non-innovative users and related segmentation-work)? How can such data be extracted from the market and applied?

In a first approximation to the answering of these questions, a more exact look at the behavioral patterns of "innovative users" is required. In this situation, one can continually observe the following phenomenon:

(1) Often innovative users and not (established) manufacturers have the greatest need for innovation because:

- a new need exists which is not (yet) being addressed by manufacturers;

- the needs at present are very specific;

- an entrance for a manufacturer is not an attractive option as a wide market is not yet recognizable;

(2) Often it is difficult and/or very expensive to transfer the required market information from users to producers as it:

- is of an experienced-based nature (tacit knowledge) and, at least by users, often not considered to be relevant;

- can't be explained in "words" (how do you teach swimming or bike riding? What is a beautiful fragrance? What is a user-friendly surface in a computer program?)

Innovative users differentiate themselves from non-innovative users as a result of, among other reasons, their possessing of new needs. Due to the fact that such new or latent needs often can't be satisfied through existing (technical) solutions and producers often aren't prepared to offer 
solutions for such needs, innovative users develop problem-solving behavior in order to satisfy their needs ("Necessity is the mother of invention"). This will allow them to develop solutionrelated knowledge (explicit and non-explicit), relevant for manufacturers investigating such fields for innovation.

To enable the market research of a company to successfully identify these innovative users by way of specific characteristics (recognition patterns), then the effectiveness and efficiency of the market research work has to improve greatly.

\section{Identification of innovative users}

A four-stage, step-wise process is described for the selection and involvement of innovative users in diagram 5. This model has proved itself in various practical applications (Herstatt/Lüthje/Lettl 2001).

Diagram 5. Process for the identification and involvement of innovative users Source: Based on von Hippel (1988), modified by the author

Various Applications of the process-model thus far have shown that the set-up of the different activities within the four phases has to be aligned with the particular requirements of the project and will be greatly influenced by external variables (e.g. development dynamics in the innovation's field, time, costs and budget pressure and planning experience of the companies' employees involved in the innovation project).

The "Lead User methodology" as it is often incorrectly referred to is in fact not a methodology rather more a basic framework. Degrees of freedom exist in particularly with regard to the arrangement of the individual phases (intensity, resources employed, method used). Two recent applications of the Lead User process showed, for example, that although both projects were carried out in identical product/market areas, the results presented two very different types for radical innovations. The projects were carried out by two leading manufacturers of hygiene products and in both cases the search field was identical ("Covering material for surgical operations"), see case 1 and 2.

\section{Case 1: $3 \mathrm{M}$}

At 3M (Medical Division) the search field of the innovation project was chosen in Phase 1 of the Lead User project as the protection from infection of patients undergoing surgery. Increasing hygiene demands, a higher resistance against antibiotics and the increasing cost pressures in clinics were identified as significant developments in the search field. With the help of a networking approach, doctors in the target market of the application were identified, who operate under extreme conditions (e.g. surgeons in development countries, veterinarians). As well as this, users from analogous fields were involved, e.g. microbiologists or make-up artists. The latter developed solutions utilizing materials that were dependable and that stick well to human skin. The results yielded improved patient coverings, a microbial-treated incision foil and a radical new approach for individual infection control allowing the delivery of the hygienic measures, tailored to the specific needs of the patient (Thomke/von Hippel/Sonnack, 1998). 


\section{Case 2: Johnson \& Johnson (J\&J)}

At J\&J the search field team concentrated on patient coverings and the protective clothing of operation personnel. In order to determine the future development trends in the search fields, talks were held with experts in different branches (surgeons, leading OP-nurses, hygiene experts). The project team decided in Phase II of the project to pursue in detail a technological trend ("surgical robotics"). During this process a group of about 20 innovative users formed themselves (surgeons as users of the robotic system, OP-personnel as being those responsible for the hygiene precautions in OP, clinical engineers as responsible for the technical evaluation and hygiene experts for infection-related questions). During a workshop four complete and detailed concepts were worked out. For example; a gown for the covering of the surgical robot, allowing the sterility and handling problems to be removed or a complete solution that allows prevention of the mist (water drops as well as bone and blood particles) generated during the operation. All four concepts worked on by the subgroups contained products that weren't at the time in the J\&J program and until now haven't been produced by any competitor in the market place (Herstatt/Lüthje/Lettl, 2001).

What can be taken from both these projects? Of central meaning for the success of both projects was that it proved fruitful to identify Lead Users early on in the project and to work together mit them to develop the concept. During the course of both projects different methodologies were pursued. Also, the number and origin of the experts and the Lead Users involved as well as the process that lead to the identification were significantly different. Finally, the internal project teams of both were differently composed in terms of expertise and in one case were intensively coached through external consultancy.

Both these Lead User projects along with those previously undertaken reinforce how the early and, as far as possible, accurate identification of innovative users is of central importance. Once they are initially identified and are prepared to involve themselves with the companies, it is of secondary importance how the market research methodologically is organized . Why? Lead Users, by definition, have today, the needs of tomorrow. Therefore there is no call for ingenious surveys or observation techniques to acquire the information relevant to the innovation.

\subsection{Characteristics of innovative users}

The innovation management of a company does not involve itself exclusively with applications for radical innovations or those for incremental. In practice, both aspects are found in more or less balanced consideration. In fact often it is not possible in day-to-day innovation work to keep these categories separate (projects that were supposed to lead to an improvement in a product, end as a new development; radical innovation plans are abandoned half way along the project or are transformed into an optimization project etc.).

What user-(types) should the innovation management involve in what type of innovation projects? Should Lead Users, as Von Hippel describes them, be involved in any project work? Are the characteristic categories determined empirically by the Lead User research to date adequate in order to recognize Lead Users prior to the start of a development project? The answering of these questions demands further research efforts.

A user typology that supports the innovation management, depending upon the need in question, in categorizing or choosing an innovative user with respect to their information contributions would certainly be useful. What would such a concrete typology look like? 
We will answer this question by analyzing several problems typically found in practice. For example, if ideas are sought for improving existing products and service performance then often it is sufficient to approach "Normal users". Example: A producer of drills that are predominately used by home handymen would like to generate ideas with the aim of improving existing features. In order to collect ideas that will be applied in a "normal" situation, it may be enough to meet with "Normal" or typical users.

The situation is different however when the aim is to improve certain functions of a product that, for example, are relevant for a particularly demanding aspect of its performance. Example: A producer of drills that are predominately used by professional tradesmen would like to collect ideas with respect to the durability of the drill bits. In order to generate ideas relating to the improvement of such features, then it is best to talk with users who for their work, this feature is of very high importance (e.g. Installation groups where the drilling machines are practically in constant use). We call them "Extreme" users.

If a manufacturer wants to scrutinize the general effectiveness of a technology and to collect information on alternatives such as suitable technological solutions, then a possibility is to analyze analogous fields. Example: A producer of drills would like to understand how the problem of drilling through extremely hard subsurfaces in other, analogous fields of applications. Discussions with operators of diamond drill machines used in oil field exploration could provide significant input and impulse innovation project. We call these "Analogous" users.

Are extreme and analogous users identical with Lead User as described by von Hippel? This question is answerable when the problem solving knowledge that is available to the innovative manufacturer has the capability to start a significant marketing and/or technological trend and possesses a broad problem solving potential for a complete user industry. Extreme users are usually found within the user industry in question, analogous users, by definition, stem from other related application fields.

This methodological approach (user typology) proved reliable in the previously mentioned project at Johnson\&Johnson. It allowed the identification of both ideas for product and process improvements as well as the recognition of promising radical innovations on the basis of the previously defined user-groups ("communities") (Diagram 6).

Diagram 6: Characterization of users based on their potential contribution to the hygiene article search field Source: Own depiction

\subsection{Search and Selection process}

The search process for suitable users is in itself a creative process that has to be tailored to the specific demands of the search field in question. Two basic processes can be described here:

(1) Screening Approach: With a large number of product users a "search pattern" can be used to test the existence of already determined characteristics. As well as that information on hand within the companies from customer data banks, complaints lists or external audit information can also be used here from customer surveys done over the telephone. This process is suitable when the number of customers in the market is manageable and therefore a more or less complete screening of all users is possible. This approach is in particular suitable to collect ideas from representative and extreme users. 
(2) Networking Approach: In this case, only a few customers are included at the beginning and are questioned as to whether they're aware of other product users that have new needs or are currently actively innovative. These kinds of recommendations usually lead very quickly to particularly interesting users. A great advantage of this method lies in the fact that the team often will refer analogous fields in which similar challenges are to be found as those in the actual search field. An example of this is a medical imaging innovation project with the aim of diagnosing very small tumors. During the search process, not only were leading radiologists involved but also experts from the military consulted as Lead Users. In order to identify small forms (e.g. weapons) on satellite images, pattern recognition software is often utilized in the military, where even with bad resolution excellent results are achievable. This application of a pattern recognition system was completely new for medical imaging because until then increasing the resolution was the primary goal of research. The networking approach is particularly suitable for the identification of extreme and analogous users.

Another question, which is also relevant in practical terms is how many expert users should be involved particularly in phases 2, 3 and 4 of the process (Diagram 4) in order to generate a satisfactory number of innovative ideas. This aspect is yet to be explicitly, academically researched. Work from Griffin and Hauser indicates that often relatively few discussions with experts (7 discussions in a group of 30 potential experts) are enough to achieve a lasting impression of the problems and needs in user field (Griffin/Hauser, 1993).

\section{Future trends, research possibilities and questions}

Innovations can, in general, be described by a high realization risk. This risk should be mitigated through systematic innovation market research. The theoretically based market research however had scarcely been thought of as an instrument to reduce market uncertainty. The question as to what contribution existing market research methodologies can perform for innovation management is not yet completely clear.

There is a bandwidth of market research methodologies for the incremental innovation field available. How can market research be used in order to obtain information of strategic relevance for radical innovations in the early phases of the innovation process?

For the early phases (idea generation and concept development), the Lead User process is particularly well suited. More precisely, this is not an actual methodology rather a procedural guide. "Lead Users" also includes analogous or extreme users from other related applications or fields. In the practical application of the Lead User process, numerous methodological and process decisions have to be made that until now haven't been sufficiently well researched (e.g. the efficient identification of innovative users, the number of users to involve etc.).

The Lead User process allows for combination during the innovation process with complementary need assessment methods or also market research methods (e.g. Conjoint Analysis, "House of Quality"). For researchers, the question still remains as to how the individual methods can be integrated into an all-encompassing concept for the market research of innovations. 


\section{Literature}

Deszca, G.; Munro, H.; Noori, H. (1999), Developing breakthrough products: challenges and options for market assessment, in: Journal of Operations Management, Vol. 17, S. 613-630

Griffin, A./Hauser, J. (1993): The voice of the customer, in: Marketing Science, Winter

Gruner, K. (1997): Kundenbindung in den Produktinnovationsprozssß, Wiesbaden (Gabler)

Hausschildt, J. (1997): Innovationsmanagement, 2. vollst. Überarb. Auflage, München (Vahlen)

Herstatt, C./Lüthje, C./Lettl, C. (2001): Innovationsfelder mit Lead Usern erschließen, Workingpaper des Lehr- und Forschungsbereichs Technologie- und Innovationsmanagement der Technischen Universität Hamburg-Harburg (forthcoming in Harvard-Manager)

Herstatt, C./Lettl, C. (2000): Management von technologiegetriebenen Entwicklungsprojekten, in: Gassmann, O./Kobe, C./Voit, E.: High-Risk-Projekte - Quantensprünge in der Entwicklung erfolgreich managen, Berlin-Heidelberg-New York

Herstatt, C./Geschka, H./Guggisberg, D./Geis, J. (1999): Innovationsbedarfserfassung in der Schweiz Methoden, Erfahrungen und Tendenzen, in: Die Unternehmung (3)

Herstatt, C./Geschka, H. (1991): Produktinnovation durch Kunden, in: Die Unternehmung (3), OktoberAusgabe

Herstatt, C. (1991): Anwender als Quellen für die Produktinnovation, Zürich

Kirchmann, E. (1994): Innovationskooperationen zwischen Herstellern und Anwendern, Deutscher Universitäts-Verlag (DUV)

Lender, F. (1991), Innovatives Technologie-Marketing: Grenzen der „konventionellen“ Marktforschungskonzepte und Ansätze zur methodischen Neugestaltung, Göttingen

Lüthje, Chr. (1999): Kundenorientierung im Innovationsprozess: Eine Untersuchung der KundenHersteller-Interaktion in Konsumgütermärkten, München

Lynn, F.; Heintz, S. (1992), From experience: Where does your new technology fit into the marketplace?, in: The Journal of Product Innovation Management, Vol. 9, Iss. 1, S. 19-25

Morrison, Pamela D./ Lillien, Gary L./ Searls, Kathleen/ Sonnack, Mary/ von Hippel, Eric (2001): „Performance assessment of the Lead User idea generation process for new product design and development", Working Paper, WP 4151, Sloan School of Management, Massachusetts Institute of Technology, Cambridge, Mass.

Schlaak, T. (1999) "Der Innovationsgrad als Schlüsselvariable: Perspektiven für das Management von Produktentwicklungen", Wiesbaden (DUV)

Shah, S. (2000), Sources and Patterns of Innovation in a Consumer Products Field: Innovations in Sporting Equipment, Sloan Working Paper \#4105, MIT Sloan School of Management

Thomke, S./von Hippel, E./Sonnack, M. Breakthrough Innovation at 3M in: Harvard Business Manager (3), 1998

Von Hippel, E. (1988), Sources of Innovation, Cambridge (US) 
